\title{
An Inexpensive Tool for Unrolling Barbed Wire
}

\author{
ROBERT W. KNIGHT, M. KARL WOOD, AND WILBERT H. BLACKBURN
}

\section{Abstract}

A hand tool for unrolling barbed wire is described which is advantageous in that it requires only one person to operate, snags are easily corrected, works in tight places, and can be constructed totally from scrap materials.

Steep, rough areas, or critically eroded soils usually require unrolling barbed wire by hand. Where expense is a problem for clearing lines through heavy brush or timber wide enough for accessibility by truck or tractor, narrow lines dictate laying wire by hand.

Methods devised for laying barbed wire by hand range from carrying the roll on a pipe or digging bar to cartlike arrangements that a person pulls (Turner 1974). The primary disadvantage of a pipe is that two people are needed for operation, and it is awkward in tight places. Most cart arrangements are expensive to build, awkward in tight places, heavy, and have limited durability.

\section{Description of the One-person Wire Roller}

This economical and easily constructed wire roller is made from an old lawn mower or similar handle and a bar (Fig. 1). The width of the handle base must accommodate a standard spool of barbed wire. A piece of $9.5 \mathrm{~mm}(3 / 8$-inch) dia. reinforcement bar or similar material holds the spool in place. A piece of scrap metal is welded to one end of the bar and a hole drilled through the other end hotds a retaining clip. The spool of barbed wire is placed on the bar and the tool pulled along the fence line (Fig. 2). Wire comes off the bottom side of the spool and is kept taut by the action of the handle and spool. If the wire snags on the roll, the person pulling the roller simply leans forward to increase tension and the snag will usually pull out. The tool can also be pulled on its side in tight places.

\section{Literature Cited}

Turner, J.H., editor. 1974. Building fences. Amer. Ass. Voc. Instructional Materials. 96 p.

Authors are graduate teaching assistants, and associate professor of watershed management, Range Science Department, Texas A\&M University, College Station, Texas 77843. Wood is now an assistant professor of watershed management, Department of Animal and Range Sciences, New Mexico State University, Las Cruces.

This technical note is a joint contribution of the Texas Agr. Exp. Sta. and the Office of Water Res. and Technol. The authors wish to acknowledge the cooperation of personnel from the Sonora Agr. Res. Sta. Approved by the Directors, Texas Agr. Exp. Sta. as TA-14426.

Manuscript received August 4, 1978.
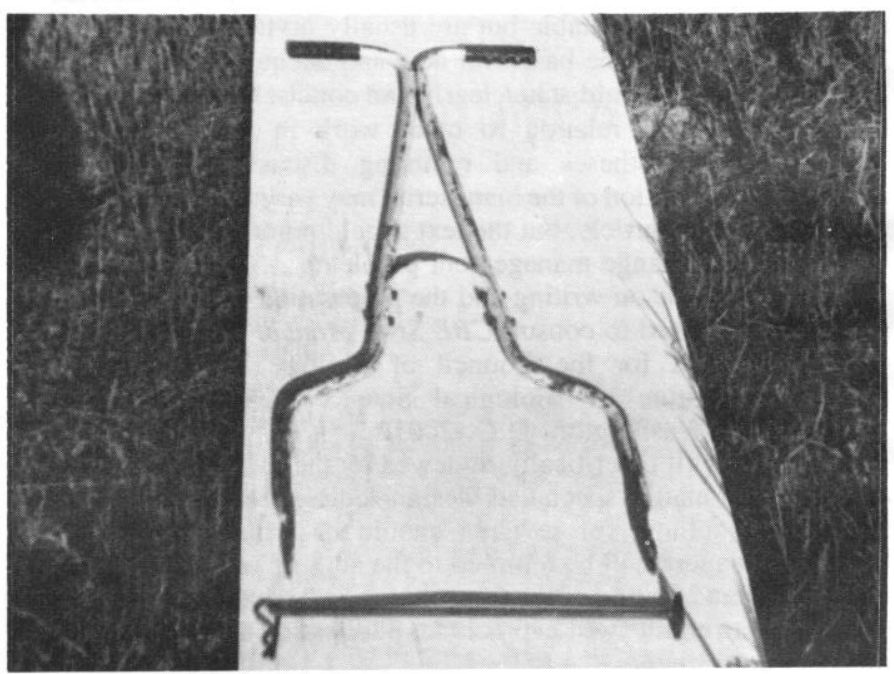

Fig. 1. Components of the one-person, barbed-wire roller include: handle from and old lawn mower (a), cross bar (b), and a retaining clip (c).

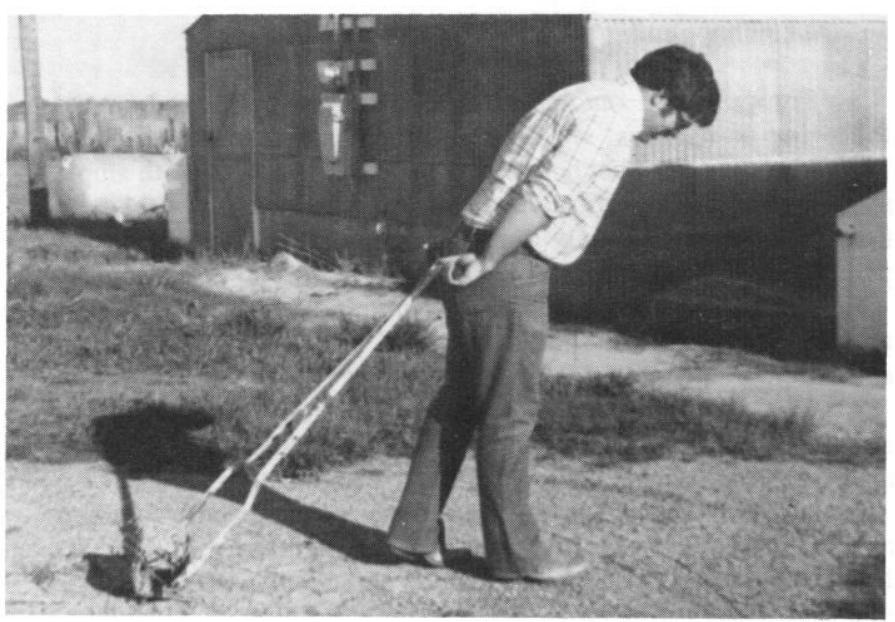

Fig. 2. The one-person, barbed-wire roller being used. 